\title{
Prevalence of Commissural Lip Pits in patients visiting a dental college in a rural area of South Kerala: A Pilot study.
}

\author{
Preeja Premakumar ${ }^{1}$, Jincy Thomas ${ }^{2}$, P. Rani $\mathrm{Mol}^{3}$, D. A. Vineet ${ }^{4}$, \\ Sunila Thomas ${ }^{5}$, V. Vivek ${ }^{6}$ \\ ${ }^{I}$ (Post graduate student, Department of oral medicine and radiology, PMS College of Dental science \& Research, India) \\ ${ }^{2}$ (Senior Lecturer, Department of oral medicine and radiology, PMS College of Dental science \& Research, India) \\ ${ }^{3}$ (Senior Lecturer, Department of oral medicine and radiology, PMS College of Dental science \& Research, India) \\ ${ }^{4}$ (Reader, Department of oral medicine and radiology, PMS College of Dental science \& Research, India) \\ 5 (Professor, Department of oral medicine and radiology, PMS College of Dental science \& Research, India) \\ ${ }^{6}$ (Professor \& Head of Department, Department of oral medicine and radiology, PMS College of Dental science \& \\ Research, India)
}

\begin{abstract}
Congenital lip pits fall among the rare congenital deformities recorded. Lip pits may develop at the commissures of the lips or in the midline. A pilot study was conducted to assess the prevalence, age distribution, site and gender predilection of commissural lip pits (CLP) in a rural population from South Kerala. A total of 11,141 patients (7984 adults and 3157 children) who visited the out patient department of PMS College of Dental Science and Research were examined over a period of one year for commissural lip pits in relation to age, gender and site. Commissural lip pits (CLP) was identified in 25 adult patients with a prevalence of $0.3 \%$ and CLP was not seen in children. The incidence of CLP was more in male patients with most numbers in the 30-35 age group, whereas in females it was more in 35-40 age group. $68 \%$ cases had unilateral lip pits with predilection for occurrence on the left side. Further studies with larger sample size are required to provide more information into various aspects of this relatively rare phenomenon.
\end{abstract}

Key words: Commissural lip pits, Pilot study, South Kerala

\section{Introduction}

Commissural lip pits (CLP) or lower lip sinuses are congenital or developmental defects that occur as singular anomalies or more often with cleft lip or palate. The defects appear as unilateral depressions or more frequently as bilateral depressions [1]. It is frequently seen as a hereditary defect, possibly a dominant characteristic and may be associated with other congenital defects $[2,3,4,5,6]$. Prevalence rates of CLP in adults ranges from 1.8-20\% [7-13]. Recent literature shows that CLP studies are mostly done in neonates or in children and that studies in adults are lacking especially in Indian population [11-14]. A dental college based pilot study was carried out to report the frequency of occurrence of commissural lip pits among patients visiting out patient department of PMS College of Dental Science \& Research situated in Vattappara, Trivandrum a rural area in South Kerala, in a one year period (Fig. 1).

\section{Materials \& Methods}

A total of 11,141 patients from Vattappara, a rural area near Trivandrum who attended the out patient department of PMS college of Dental Science \& Research over a period of one year from May 2012 to April 2013, willing to participate in this study were examined for clinical evidence of commissural lip pits. The data on age, gender and site of the lesion were recorded. Diagnosis of commissural lip pits were made based on clinical examination. Ethical clearance was obtained from the institutional ethical committee for the study.

\section{Results}

Out of 11,141 patients examined (7984 adults and 3157 children) commissural lip pits were identified in 25 adult patients in the ages ranging from 23 to 48 years, with $0.3 \%$ prevalence. No cases of CLP were identified in the 3157 children examined. Out of 25 patients with CLP, sixteen were males (64\%) and nine were females (36\%) with a male: female ratio 2:1 (Fig. 2). In males, the incidence of CLP was found to be more in the age group 30 to 35 years (6 out of 25) and in females it was more in the age group 35-40 years (5 out of 25) ( Fig. 3). Of the patients with CLP, Bilateral CLP was seen in $32 \%$ cases ( $8 / 25$ cases) and $68 \%(17 / 25)$ presented with unilateral CLP. Of the 17 patients with unilateral lesion, twelve patients presented with commissural lip pit on the left side (Fig. 4). 


\section{Discussion}

Commissural lip pits are entities related to lip pits, but occur on the lip commissures lateral to the typical lip pits. Lip pits can occur either as an isolated defect or in association with other developmental disturbances as a Popliteal Pterygium syndrome [4], Van der Woude's syndrome [5], Oro-facial -digital syndrome and Marves and Cremer's syndrome [6]. CLP appear as unilateral or bilateral pits at the corners of the mouth on the vermillion surface.

In India, a study conducted for oral mucosal lesions in 1003 school children of age group 4-14 years, $3.5 \%$ children had CLP and that too, bilateral presentation [11]. In our study we observed an overall prevalence of $0.3 \%$ with maximum incidence in the 30 to 35 year age group in males and 35-40 years in females, whereas no CLP was identified in children. Several studies indicate a male predilection for commissural lip pit $[12,13]$. In a study, by Sedano et al. involving 32,022 Mexican children examined for congenital oral and paraoral anomalies, boys presented with more commissural lip pits (53.1 per 1000) than girls (52.4 per 1000) [13]. A slight male predilection was observed in an Argentinean study involving 6,180 school age children, where 29 students out of 52 patients presenting with CLP were males and 23 were females [12]. Similarly an Israeli study has also reported a male predilection [9]. However a male: female ratio of 1:1 was observed in an US study [10]. Our study showed male predilection with male: female ratio of 2:1.

Most studies on CLP, report unilateral involvement more than bilateral $[9,13]$. In a Mexican study, $31 \%$ of the patients with commissural lip pits had bilateral lip pits and $69 \%$ showed unilateral involvement with left side more involved than the right [13]. In Israeli population with CLP 9.7\% had unilateral lip pits and 7.7\% cases of bilateral cases [9]. However a study on 500 neonates in Memphis, Tennessee $1.2 \%$ cases presented with unilateral and $8 \%$ had bilateral lip pits [14]. In our study, $68 \%$ presented with unilateral lip pits and only $32 \%$ showed bilateral lip pits. Of the unilateral lip pits $48 \%$ were on the left side and $20 \%$ on the right. Our study results were in accordance to the observations made by Sedano et al [13].

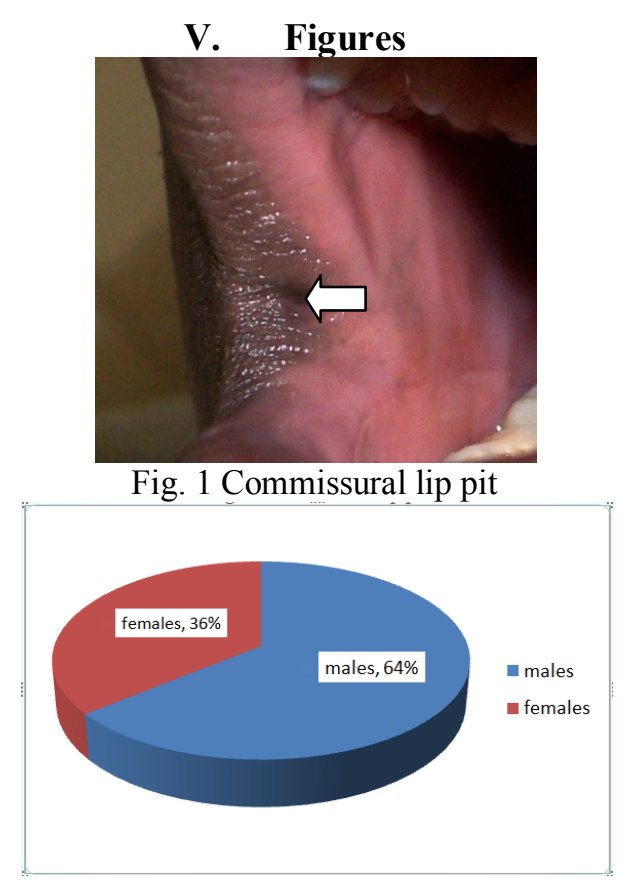

Fig. 2 gender distribution

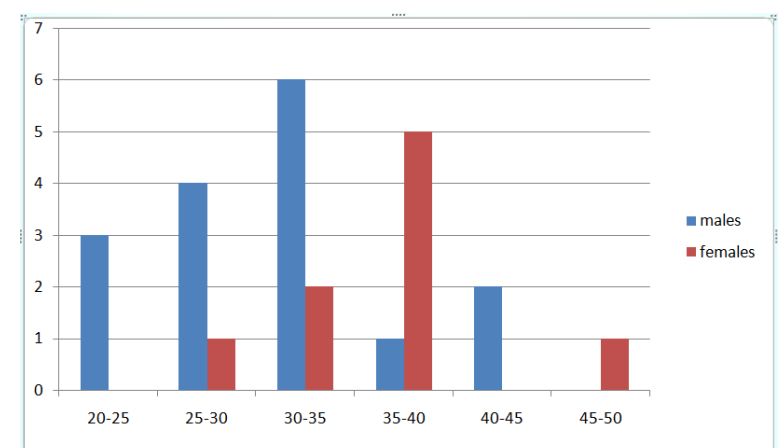

Fig. 3 age group of males and females with commissural lip pits 


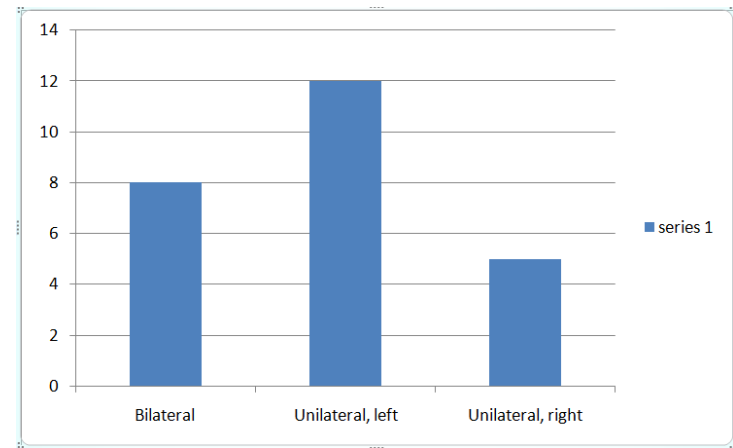

Fig. 4 Site wise distributions

\section{Conclusion}

In our study the prevalence of isolated commissural lip pits in adults was $0.3 \%$ with a male predilection and there were no cases of CLP observed in children. Unilateral cases of CLP were more common with left side being affected most. Though lip pits can be associated feature of certain syndromes, there were no syndromic patients in our study. A comprehensive study with a much larger sample size will throw more light into various aspects of this relatively rare phenomenon.

\section{Clinical Significance}

Other than aesthetic defects, CLP is a developmental malformation that rarely presents problems for the patient. However it can often make the patient susceptible to angular cheilitis. Because of its association with Popliteal Pterygium syndrome, Van der Woude's syndrome, Oro-facial -digital syndrome and Marves and Cremer's syndrome the presence of CLP should alert the clinician to the possibility of other developmental malformations.

\section{References}

[1]. Velez A, Congenital lower lip pits (Van der Woude's Syndrome) J Am Acad Dermatol, 3(1), 1995, 520-521

[2]. Rajendran R, Developmental Disturbances of Oral and para oral structures, in: Rajendran R, Sivapathasundaram B (Ed), Shafer's Textbook of Oral Pathology, 6 (India: Elsevier, 2009) 1-80.

[3]. Barker B.F, Lesions of the lips, in: Wood N.K, Goaz P.W (Ed), Differential Diagnosis of Oral and Maxillofacial Lesions, 5 (India: MOSBY, 2006) 561-579.

[4]. Herold HZ, Samuel G, Baruchin AM, Popliteal pterygium synd. Clin Orthop, 4(2), 1986, $209-214$.

[5]. Schinezel A, Klausler M. The Van der Woude's Syndrome (dominantly inherited lip pits and clefts). J Med Genet, 23(1), 1986, 291292.

[6]. Marres HA, Gremers CW, Congenital conductive or mixed deafness, preauricular sinus, external ear anomaly and commissural lip pits: An A.D. inherited syndrome, Ann Oto rhino laringol, 10(1), 1991, 928-929.

[7]. Neville WB, Damm DD, Allen MC, Bouquot JE, Developmental Defects of the Oral and Maxillofacial Region (India, Elsevier, 2002).

[8]. Freudenberger S, Santos M, Bravo JM, Sedano HO, Intraoral Findings and other Developmental Conditions in Mexican Neonates, Journal of Dentistry for Children, 3(2), 2008, 280-285.

[9]. Gorsky M, Buchner A, Cohen C, Commissural lip pits in Israeli Jews of different ethnic origin, Community Dent Oral Epidemiol, 13(1), 1985, 195-196.

[10]. Bonquot JE, Gundlach KKH, Odd lips: the prevalence of common lip lesions in 23,616 white Americans over 35 years of age, Quint Internat 18(1), 1987, 277-284.

[11]. Ambika L, Keluskar V, Hugar S, Patil S, Prevalence of oral mucosal lesions and variations in Indian public school children, Brazilian Journal of Oral Sciences, 10(1), 2011, 288-293.

[12]. Sedano H.O, Congenital oral anomalies in Argentinian children, Community Dent. Oral Epidermiol, 3(1), 1975, 61-63.

[13]. Sedano H.O, Carreon Freyre I, Garza de la Garza ML, Gomar Franco CM, Grimaldo Hernandez C, Hernandez Montoya ME, Hipp C, Keenan KM, Martinez Bravo J and Medina Lopez JA, Clinical orodental abnormalities in Mexican children, Oral Surg Oral Med Oral Pathol, 68(3), 1989, 300-311.

[14]. Friend G.W, Harris E.F, Mincer H.H, Fong T. L and Carruth K.R, Oral anomalies in the neonate, by race and gender, in an urban setting, Pediatric Dentistry, 12(1), 1990, 157-161. 